OPEN ACCESS

Edited by:

Silvia Collado,

University of Zaragoza, Spain

Reviewed by:

Stephany Hess Medler,

University of La Laguna, Spain

Paola Passafaro,

Sapienza University of Rome, Italy

${ }^{*}$ Correspondence:

Stepan Vesely

stepan.vesely@ntnu.no

Specialty section:

This article was submitted to

Environmental Psychology,

a section of the journal

Frontiers in Psychology

Received: 23 March 2020

Accepted: 25 May 2020

Published: 24 July 2020

Citation:

Vesely S and Klöckner CA (2020)

Social Desirability in Environmental

Psychology Research: Three Meta-Analyses.

Front. Psychol. 11:1395.

doi: 10.3389/fpsyg.2020.01395

\section{Social Desirability in Environmental Psychology Research: Three Meta-Analyses}

\author{
Stepan Vesely* and Christian A. Klöckner \\ Department of Psychology, Norwegian University of Science and Technology, Trondheim, Norway
}

That social desirability might be a confounder of people's survey responses regarding environmental actions has been discussed for a long time. To produce evidence for or against this assumption, we conducted meta-analyses of correlations between social desirability scales and self-reports of environmentally relevant behaviors, intentions, and (broadly defined) attitudes, based on data from 29 previously published papers. The pooled correlations with social desirability are generally small, ranging from 0.06 to 0.11 (0.08-0.13 when correcting for measurement error attenuation). However, our results do not lead to the conclusion that social desirability can be completely disregarded by environmental psychologists as a potential confounder. For example, we found evidence of substantial heterogeneity across studies, so the effect of social desirability may be more pronounced in specific cases. Continued attention to social desirability bias is needed to fully understand its possible subtle effects. Keywords: social desirability, proenvironmental behaviors, proenvironmental intentions, environmental attitudes,
meta-analysis

\section{INTRODUCTION}

The majority of research on people's environmental behavior and its antecedents and consequences is conducted using surveys where people self-report their actions, beliefs, attitudes, and other sociopsychological variables (Lange and Dewitte, 2019). For a behavior that is morally relevant, such as proenvironmental behavior, it is not unlikely that people bias their responses to achieve a better social impression of themselves (e.g., Kaiser et al., 1999). This raises the question of how reliable research on environmental behavior and its antecedents is. Being prone to social desirability in answering survey questions may potentially bias people's answers to a degree where the accuracy and practical relevance of the findings is threatened.

Consequently, social desirability has been often viewed as a potential confounding variable in environmental psychology research (Kaiser et al., 1999; Bruni and Schultz, 2010; Cerri et al., 2019). On the other hand, there is also evidence suggesting that social desirability may only play a relatively minor role (e.g., Milfont, 2009; O’Brien et al., 2018; see also McGrath et al., 2010; Paunonen and LeBel, 2012). The task of the present meta-analyses is therefore to systematically evaluate existing research on the links between social desirability and various key measures used in environmental psychology studies, in particular self-reported behavior, intention, and a number of general attitudinal measures like the New Environmental Paradigm (Dunlap and Van Liere, 1978; Dunlap et al., 2000) and connectedness to nature (Mayer and Frantz, 2004; Tam, 2013a). 
Social desirability can be understood as research participants' tendency to bias their responses in surveys and experiments in order to appear in a more favorable light (Crowne and Marlowe, 1960). A typical example is participants reporting that they regularly sort and recycle household waste even if this is not in fact true. This type of misreporting may then in part account for the often observed mismatch between self-reported and observed proenvironmental behavior (see Kormos and Gifford, 2014). The reasons underlying such biased responding primarily include the avoidance of negative social sanctions like disapproval and ostracism and the seeking of social rewards like approval and higher social status (Crowne and Marlowe, 1960, 1964; Rasinski et al., 1999). However, since participants' responses are often anonymous, this could in part dispel social desirability bias by eliminating opportunities for subsequent social sanctioning (Paulhus, 1984; Lautenschlager and Flaherty, 1990; Joinson, 1999; Dodou and de Winter, 2014; but see Singer et al., 1992; Fox and Schwartz, 2002). On the other hand, people are implicitly attuned even to subtle cues of observation, so the mere presence of an experimenter or other participants may conceivably trigger some level of socially desirable responding despite explicit assurances of anonymity (see Hoffman et al., 1996; Haley and Fessler, 2005).

There are several ways in which socially desirable responding may potentially affect findings, such as adding noise to data, increasing or decreasing mean scores, constraining the variability of responses, and inflating, suppressing, and moderating correlations between variables (Ganster et al., 1983; Kaiser et al., 2008; Bruni and Schultz, 2010; Paunonen and LeBel, 2012; Zhang W. Z. et al., 2014). Recognizing the potentially serious consequences of social desirability bias, a number of different methods how to address it have been proposed, but each of them has limitations of their own: Other-reported measures (obtained by gathering data on the target individuals' behavior and characteristics from third-party observers), for example, may suffer from the observer not being able to properly observe the target's behavior (Chao and Lam, 2011; Grønhøj and Thøgersen, 2012; Matthies et al., 2012; Seebauer et al., 2017). Implicit measures may fail to fully capture conscious attitudes and beliefs that also come to play when making actual decisions (see Bruni and Schultz, 2010; Thomas and Walker, 2016; Brick and Lai, 2018). The indirect questioning technique (where participants' beliefs about others' behavior are treated as a proxy for selfreports of participants' own behavior) can be said to in part tap perceived descriptive norms, rather than to indirectly measure own behavioral tendencies (see, e.g., Lusk and Norwood, 2010; Klaiman et al., 2016). The scope of behaviors and beliefs that can be assessed through incentivized and objective measures is restricted (Schultz et al., 2007; Juhl et al., 2017; Vesely and Klöckner, 2018). For additional approaches of coping with social desirability bias, see, e.g., Warner (1965), Paulhus (1981), Nederhof (1985), Krumpal (2013), Korndörfer et al. (2014).

Another major way of dealing with social desirability bias is to measure the tendency a person has for responding in a socially desirable manner and use this as a control variable in survey studies to adjust results for the individual bias. In this work, we focus specifically on such questionnaire measures of social desirability, for instance the seminal scales due to Crowne and Marlowe (1960) and Paulhus (1991). Research in several other domains-for example, personality psychology, work and organizational psychology, and health-related researchemploys these instruments to detect socially desirable responding (e.g., Ones et al., 1996; Li and Bagger, 2006; van de Mortel, 2008; Bäckström et al., 2009; Davis et al., 2010; Zemore, 2012). An advantage of questionnaire measures is that they tap social desirability directly and allow subsequent partialling out of this variable in statistical analyses (see, e.g., Davis et al., 2009; Howell et al., 2011; Tam, 2013b; Cojuharenco et al., 2016). In contrast, when comparing, for example, self-reported, other-reported, and observed behaviors (Corral-Verdugo, 1997; Chao and Lam, 2011; Kormos and Gifford, 2014) or incentivized and nonincentivized responses (Camerer and Hogarth, 1999), isolating the effect of social desirability is often not straightforward, as other factors, including inattention and imperfect recall, may account for some of the differences between the compared study variables (see Hough et al., 1990; Oppenheimer et al., 2009; Meade and Craig, 2012).

The inclusion of social desirability measures in environmental psychological research has also another advantage that we are going to utilize in our study. It allows to quantify if there actually is a confound of measures of proenvironmental behavior or its predictors with social desirability. In other words, we can test if people more prone to social desirability are scoring systematically different on the behavior-related variables than people with lower social desirability scores. Since a growing number of studies of proenvironmental behavior also include social desirability measures (even if the number of studies is still restricted), we deem the time right for testing the hypothesis of a significantly positive relation between social desirability and self-reports of proenvironmental behavior, attitudes, and intentions in a metaanalytical setting. To our knowledge, such a meta-study has not been conducted before, so we provide valuable knowledge on a question of high importance for the interpretation of many studies in environmental psychology.

\section{METHOD}

\section{Inclusion Criteria}

The following criteria were applied to select studies for inclusion in our meta-analyses:

(1) The study had to be published in a scientific journal or in an edited book in English.

(2) The study had to include at least one of the following measures: (a) environmentally relevant behavior, (b) environmentally relevant behavioral intention, (c) environmentally relevant attitudinal measure (broadly defined), which, for our purposes, encompasses specifically any of the following measures: environmental attitude, environmental concern, environmental or ecological worldview, biospheric values, connectedness to nature, and environmental identity. As for our treatment of the "attitudinal measures," we decided to group these conceptually related, albeit distinct, variables together due to limited data availability (for example, only four relevant 
TABLE 1 | Overview of studies included in the meta-analyses.

\begin{tabular}{|c|c|c|c|c|c|}
\hline Meta-analysis & $\boldsymbol{k}$ & Included studies & $r$ & $r_{\mathrm{c}}$ & $n$ \\
\hline \multirow[t]{27}{*}{$\begin{array}{l}\text { Proenvironmental } \\
\text { behavior and } \\
\text { social desirability }\end{array}$} & \multirow[t]{27}{*}{27} & $\begin{array}{l}\text { Bratt et al. (2015) - combined } \\
\text { sample (Norway and } \\
\text { Germany) }\end{array}$ & 0.12 & 0.12 & 2,161 \\
\hline & & Chan et al. (2008) & 0.05 & 0.06 & 250 \\
\hline & & Chao and Lam (2011) & 0.12 & 0.12 & 172 \\
\hline & & Cojuharenco et al. (2016) & 0.14 & 0.17 & 638 \\
\hline & & Hatfield and Job (2001) & -0.15 & -0.15 & 80 \\
\hline & & Haws et al. (2014) -Study 1a & 0.00 & 0.00 & 264 \\
\hline & & Kaiser et al. (1999) - Study 1 & -0.13 & -0.17 & 445 \\
\hline & & Kaiser et al. (1999) -Study 2 & 0.29 & 0.39 & 488 \\
\hline & & Lacasse (2019) & 0.01 & 0.01 & 114 \\
\hline & & $\begin{array}{l}\text { Mayer and Frantz } \\
\text { (2004)-Study } 2\end{array}$ & 0.22 & 0.32 & 65 \\
\hline & & Milfont (2009) - Study 1 & 0.13 & 0.17 & 332 \\
\hline & & Milfont (2009)-Study 2 & 0.13 & 0.19 & 314 \\
\hline & & Moon et al. (2016) & 0.11 & 0.16 & 784 \\
\hline & & O'Brien et al. (2018) - Study 2 & 0.15 & 0.21 & 227 \\
\hline & & Oerke and Bogner (2013) & 0.33 & 0.40 & 198 \\
\hline & & Panno et al. (2015) & -0.02 & -0.03 & 299 \\
\hline & & Pepper et al. (2011) & 0.33 & 0.46 & 532 \\
\hline & & Pfattheicher et al. (2016) & 0.02 & 0.03 & 1935 \\
\hline & & Raineri and Paille (2016) & 0.03 & 0.04 & 531 \\
\hline & & Sörqvist et al. (2015a) & -0.18 & -0.18 & 48 \\
\hline & & $\begin{array}{l}\text { Sörqvist et al. (2015b) - Study } \\
\text { 2, Grapes subsample }\end{array}$ & -0.20 & -0.20 & 48 \\
\hline & & $\begin{array}{l}\text { Sörqvist et al. (2015b) - Study } \\
\text { 2, Raisins subsample }\end{array}$ & 0.02 & 0.02 & 48 \\
\hline & & $\begin{array}{l}\text { Sörqvist et al. (2015b) - Study } \\
3\end{array}$ & 0.04 & 0.04 & 48 \\
\hline & & Tam (2013b) - Study 2 & 0.18 & 0.20 & 172 \\
\hline & & Ture and Ganesh (2018) & 0.22 & 0.23 & 383 \\
\hline & & Wu and Yang (2018) & 0.37 & 0.37 & 541 \\
\hline & & Zhao et al. (2018) & 0.09 & 0.12 & 529 \\
\hline \multirow{12}{*}{$\begin{array}{l}\text { Proenvironmental } \\
\text { intention and } \\
\text { social desirability }\end{array}$} & \multirow[t]{12}{*}{12} & Chan et al. (2008) & 0.12 & 0.15 & 250 \\
\hline & & Chao and Lam (2011) & 0.18 & 0.18 & 172 \\
\hline & & Haws et al. (2014) -Study 1a & -0.03 & -0.03 & 264 \\
\hline & & Kaiser et al. (1999) - Study 1 & -0.11 & -0.14 & 445 \\
\hline & & Kaiser et al. (1999) - Study 2 & 0.24 & 0.32 & 488 \\
\hline & & Lapinski et al. (2017) & 0.18 & 0.21 & 319 \\
\hline & & Moon et al. (2016) & 0.04 & 0.04 & 784 \\
\hline & & Mydock et al. (2018) & 0.20 & 0.25 & 79 \\
\hline & & O'Brien et al. (2018) -Study 2 & 0.00 & 0.00 & 227 \\
\hline & & $\begin{array}{l}\text { Sörqvist et al. (2015b) - Study } \\
\text { 2, Grapes subsample }\end{array}$ & 0.01 & 0.01 & 48 \\
\hline & & $\begin{array}{l}\text { Sörqvist et al. (2015b) -Study } \\
\text { 2, Raisins subsample }\end{array}$ & 0.11 & 0.11 & 48 \\
\hline & & $\begin{array}{l}\text { Sörqvist et al. (2015b) - Study } \\
3\end{array}$ & -0.03 & -0.03 & 48 \\
\hline \multirow{3}{*}{$\begin{array}{l}\text { General } \\
\text { proenvironmental } \\
\text { attitude and social } \\
\text { desirability }\end{array}$} & \multirow[t]{3}{*}{23} & $\begin{array}{l}\text { Bratt et al. (2015) - German } \\
\text { sample }\end{array}$ & 0.02 & 0.03 & 967 \\
\hline & & $\begin{array}{l}\text { Bratt et al. } \\
\text { (2015) - Norwegian sample }\end{array}$ & 0.00 & 0.00 & 880 \\
\hline & & Cojuharenco et al. (2016) & -0.06 & -0.08 & 638 \\
\hline
\end{tabular}

(Continued)
TABLE 1 | Continued

\begin{tabular}{|c|c|c|c|c|c|}
\hline Meta-analysis & $k$ & Included studies & $r$ & $r_{\mathrm{c}}$ & $n$ \\
\hline & & Haws et al. (2014) - Study 1a & 0.00 & 0.00 & 264 \\
\hline & & Howell et al. (2011) -Study 1 & 0.05 & 0.07 & 452 \\
\hline & & Howell et al. (2011)-Study 2 & 0.17 & 0.21 & 275 \\
\hline & & Kaiser et al. (1999) -Study 1 & -0.01 & -0.01 & 445 \\
\hline & & Kaiser et al. (1999) -Study 2 & 0.19 & 0.26 & 488 \\
\hline & & Lacasse (2019) & 0.05 & 0.06 & 122 \\
\hline & & Lapinski et al. (2017) & 0.18 & 0.21 & 319 \\
\hline & & $\begin{array}{l}\text { Lavergne and Pelletier } \\
\text { (2015)-Study } 2\end{array}$ & 0.17 & 0.26 & 257 \\
\hline & & $\begin{array}{l}\text { Mayer and Frantz } \\
\text { (2004)-Study } 2\end{array}$ & 0.15 & 0.23 & 65 \\
\hline & & Milfont (2009) -Study 1 & -0.03 & -0.04 & 332 \\
\hline & & Milfont (2009) -Study 2 & 0.12 & 0.15 & 314 \\
\hline & & Mydock et al. (2018) & -0.24 & -0.31 & 79 \\
\hline & & O'Brien et al. (2018) -Study 2 & 0.09 & 0.11 & 227 \\
\hline & & Oerke and Bogner (2013) & 0.20 & 0.25 & 198 \\
\hline & & Raineri and Paille (2016) & 0.02 & 0.03 & 531 \\
\hline & & Sörqvist et al. (2015a) & 0.14 & 0.16 & 48 \\
\hline & & Tam (2013b) -Study 2 & 0.18 & 0.21 & 172 \\
\hline & & Ture and Ganesh (2018) & 0.11 & 0.13 & 383 \\
\hline & & Wiseman and Bogner (2003) & 0.04 & 0.04 & 805 \\
\hline & & $\begin{array}{l}\text { Zhang J. W. et al. } \\
\text { (2014)-Study } 2\end{array}$ & -0.05 & -0.07 & 151 \\
\hline
\end{tabular}

studies included a connectedness to nature measure). We do not wish to imply that these variables measure the same construct (see, e.g., Kaiser et al., 2013). The many similarities and substantial empirical associations among these measures may nevertheless justify grouping them together for the present purposes (see, e.g., Milfont and Duckitt, 2010; Kaiser et al., 2013; Martin and Czellar, 2017).

(3) The study had to include a measure of social desirability.

(4) Correlation(s) between the respective environmentally relevant measures and the social desirability scale, along with the associated sample size on which the correlation(s) were based, had to be reported in the paper or be available upon request from the author(s) of the respective article.

\section{Literature Search and Selection of Studies Literature Search}

We located papers potentially relevant for our analyses using four search strategies:

(1) The first strategy consisted of searching the Web of Science database platform using a combination of search terms such as "social* desirab*," "proenvironmental," and "environmentally conscious." The exact search string we used is reproduced in Appendix. This way, we located 19,141 potentially relevant papers.

(2) Next, we scanned full texts of all papers published in Journal of Environmental Psychology and Environment and Behavior between the years 2000 and 2019 and in Frontiers 
in Psychology: Environmental Psychology between the years 2016 and 2019. This way, we identified 15 additional potentially relevant papers.

(3) The third search strategy consisted of ancestry and descendancy searches. This yielded 21 additional potentially relevant papers.

(4) Finally, we included 11 additional potentially relevant papers previously known to the authors.

\section{Selection of Studies}

In the next step, we screened the abstracts of all papers located via the above search strategies, retaining those papers that could not be unequivocally excluded based on the inclusion criteria presented in Inclusion Criteria. This resulted in a selection of 211 potentially relevant papers. Full texts of all these papers were then inspected to determine whether they met our inclusion criteria. Twenty-nine papers $\operatorname{did}^{1}$.

\section{Overview of Analysis}

Several studies, for example O'Brien et al. (2018), contained multiple relevant "outcome variables" (i.e., environmental behavior, environmental intention, or environmental attitude, see Inclusion Criteria) or multiple measures of social desirability (e.g., Haws et al., 2014). To ensure independence of observations included in a meta-analysis (Hunter and Schmidt, 1990), we therefore conducted three separate meta-analyses, with each of the outcome variables (intention, behavior, and attitude) studied separately. Furthermore, when a study contained multiple outcome variables of the same type (such as two different intention measures) or multiple social desirability measures, we aggregated the respective correlations following the shifting unit of analysis method proposed by Cooper (1998).

Following these procedures, we arrived at the set of correlations extracted from primary studies, which are listed in Table 1 in Results. There, we also report correlations corrected for measurement error attenuation (Spearman, 1904). When reliabilities were not reported or when single-item scales were used, we assigned a reliability value of 1 in order to compute the corrected correlation (Manning, 2009).

Before estimating the population effect size, we converted the correlations from primary studies to a standard normal metric using Fisher $r$-to- $Z$ transformation (Hedges and Olkin, 1985). The population $Z$ scores that we obtained were then transformed back to $r$. We obtained the estimate of the correlation size in the population from which the observations (here, correlations extracted from primary studies) were drawn by estimating a random effects model. Random effects models assume the presence of unidentified sources of variance that are randomly distributed across studies (e.g., due to different procedures used to collect data). This assumption was supported by a series of highly significant $Q$ tests (reported in Table 2 below), which reject homogeneity in correlations across studies included in a given meta-analysis. Pooled correlations were estimated

\footnotetext{
${ }^{1}$ To avoid double counting, we dropped the paper by Hartig et al. (2001) from the analysis, despite meeting our inclusion criteria, since the same data were also reported in Kaiser et al. (1999), a paper that we include.
}

TABLE 2 | Pooled correlations with social desirability.

\begin{tabular}{|c|c|c|c|}
\hline & $\begin{array}{l}\text { Outcome } \\
\text { variable }\end{array}$ & $\begin{array}{c}\text { Pooled effect } \\
\text { size (95\% LLCI, } \\
95 \% \text { ULCI) }\end{array}$ & $\boldsymbol{Q}$ \\
\hline \multirow{3}{*}{$\begin{array}{l}\text { Meta-analyses based on } \\
\text { correlations not corrected } \\
\text { for measurement error } \\
\text { attenuation }\end{array}$} & $\begin{array}{l}\text { Proenvironmental } \\
\text { behavior }\end{array}$ & $\begin{array}{c}0.11(0.06 \\
0.16)^{\star \star \star}\end{array}$ & $174.75^{\star \star \star}$ \\
\hline & $\begin{array}{l}\text { Proenvironmental } \\
\text { intention }\end{array}$ & $0.08(0.00,0.15)^{\star}$ & $42.64^{\star \star \star}$ \\
\hline & $\begin{array}{l}\text { Proenvironmental } \\
\text { attitude }\end{array}$ & $0.06(0.03,0.10)^{\star \star}$ & $58.30^{\star \star \star}$ \\
\hline \multirow{3}{*}{$\begin{array}{l}\text { Meta-analyses based on } \\
\text { correlations corrected for } \\
\text { measurement error } \\
\text { attenuation }\end{array}$} & $\begin{array}{l}\text { Proenvironmental } \\
\text { behavior }\end{array}$ & $\begin{array}{c}0.13(0.07 \\
0.19)^{\star \star \star}\end{array}$ & $270.24^{* \star \star}$ \\
\hline & $\begin{array}{l}\text { Proenvironmental } \\
\text { intention }\end{array}$ & $\begin{array}{c}0.09(-0.00 \\
0.19)^{\dagger}\end{array}$ & $67.84^{\star \star \star}$ \\
\hline & $\begin{array}{l}\text { Proenvironmental } \\
\text { attitude }\end{array}$ & $0.08(0.03,0.13)^{\star \star}$ & $99.52^{\star \star \star}$ \\
\hline
\end{tabular}

$$
\begin{aligned}
& { }^{\dagger} p<0.051 . \\
& { }^{\star} p<0.05 . \\
& { }^{* *} p<0.01 . \\
& { }^{\star * *} p<0.001 .
\end{aligned}
$$

by weighing the observations by the inverse of a variance term including both their within- and between-study variance components (DerSimonian and Laird, 1986; Hedges and Vevea, 1998).

\section{RESULTS}

For each of our three meta-analyses (with proenvironmental behavior, proenvironmental intention, and proenvironmental attitude, respectively, serving as the outcome variable), Table 1 lists the number of correlations from primary studies included in the meta-analysis $(k)$, along with a more detailed information on the actual studies included, the correlations with social desirability extracted from each study $(r)$, the correlations with social desirability corrected for measurement error attenuation $\left(r_{\mathrm{c}}\right.$, computed according to Spearman, 1904), and the number of participants on which the respective within-study correlations are based $(n)^{2}$.

Table 2 presents the main results. In the upper half of the table, we report calculations based on correlations not corrected for measurement error attenuation, while the lower part of the table presents calculations based on correlations corrected for measurement error attenuation (which are generally slightly larger). In the third column, we report population estimates of the size of the correlation between social desirability and the respective outcome variable (listed in the second column),

\footnotetext{
${ }^{2}$ In a few instances when additional information not reported in the original article was requested from the authors, the data we obtained differed slightly from what the data would have looked liked if it was possible to reproduce the analyses exactly as they were performed in the original article. For example, information on the exact data cleaning procedures used in the original article may have been no longer available to the authors of the original article, and thus, the additional analyses they sent us may have been based on a slightly larger or smaller sample than the analyses reported in their original article. However, it seems unlikely that this could bias our results.
} 
with $95 \%$ confidence intervals in brackets. As one can see, the pooled correlations are all small. All correlations are nevertheless statistically significantly larger than zero.

In the last column of Table 2, we report Cochran's Q. A significant $Q$ statistic suggests the presence of heterogeneity in effect sizes across studies within a given meta-analysis. This might indicate the influence of moderator variables that render the effects relatively more pronounced in certain cases. However, due to the relatively small number of studies included in each meta-analysis, we decided against performing moderator analyses.

\section{CONCLUSIONS}

Our meta-analyses of existing evidence on the links between social desirability and proenvironmental behaviors, intentions, and (broadly defined) attitudes show the effects of social desirability to be small (Cohen, 1988; Richard et al., 2003). It does not follow, however, that environmental psychologists should simply ignore social desirability issues as a result. First of all, the evidence available up to date is somewhat sparse, and future studies incorporating social desirability scales would be valuable in order to gain more robust and refined insights. The scarcity of available evidence, for example, does not allow us to draw any firm conclusions with respect to the type of self-reported environmental behaviors that may be comparatively more prone to socially desirable responding. Presumably, this might concern especially behaviors, the performance of which is more strongly associated with social sanctions and social status (Griskevicius et al., 2010; Brooks and Wilson, 2015).

A second important point to make is that social desirability may bias responses obtained from different people in opposite directions, which could in turn attenuate the overall correlation that we observe. For instance, people holding proenvironmental beliefs may bias their self-reported behavior upwards, while people holding less proenvironmental or even antienvironmental convictions may underreport their sustainable behaviors (Brick et al., 2017). To shed more light on this hypothesis of social desirability steering responses of different types of people in opposite directions, future studies can include social and personal norms (e.g., Thøgersen, 2006) and identity variables (e.g., Whitmarsh and O'Neill, 2010) as potential moderators of the links between social desirability and relevant selfreported measures.

It is also possible that popular social desirability scales (Crowne and Marlowe, 1960; Paulhus, 1991) are too general in their focus to fully capture socially desirable response tendencies specific to contexts studied in environmental psychology and related disciplines. A promising approach to help address this

\section{REFERENCES}

Bäckström, M., Björklund, F., and Larsson, M. R. (2009). Five-factor inventories have a major general factor related to social desirability which can be reduced by framing items neutrally. J. Res. Pers. 43, 335-344. doi: 10.1016/j.jrp.2008.12.013 issue may be the development of social desirability scales tailormade for the specific context at hand (see Ewert and Galloway, 2009 for an initial step in this direction).

Yet another subtle way in which social desirability may operate is by influencing the level of consistency among different elicited responses (Ganster et al., 1983; Hough et al., 1990; Milfont, 2009; Oerke and Bogner, 2013). Simply looking at the correlation between an outcome variable and social desirability would not pick up this type of bias: one needs to look at the way in which social desirability may interact with a predictor in determining the dependent variable (cf. Milfont, 2009; Oerke and Bogner, 2013).

Our results suggest that it is unlikely that controlling for social desirability alone would be enough to obtain entirely unbiased attitudinal and behavioral measures. Future research in environmental psychology should therefore pay increased attention also to other so far often neglected sources of measurement error, such as imperfect recall, lack of comprehension, and careless responding (for examples of studies attempting to address some of these issues, see Bissing-Olson et al., 2016; Brick and Lewis, 2016; Cojuharenco et al., 2016; Gorissen and Weijters, 2016; Hahnel and Brosch, 2018).

In conclusion, the present meta-analyses provide a reliable assessment of available evidence on social desirability effects in environmental psychology. The effects are small, but we recommend including social desirability scales as control variables in environmental psychology studies to enhance internal validity and to generate more data that can be subsequently used to evaluate also possible subtle effects of social desirability discussed earlier in this section (e.g., social desirability concerns leading some people to overreport, but others to underreport their environmental behavior, cf. Brick et al., 2017).

\section{DATA AVAILABILITY STATEMENT}

All datasets presented in this study are included in the article/supplementary material.

\section{AUTHOR CONTRIBUTIONS}

Both authors contributed to all aspects of this work (design, analysis, and writing).

\section{FUNDING}

Open access fees for this article are covered by Norwegian University of Science and Technology's Publishing Fund. 
*Bratt, C., Stern, P. C., Matthies, E., and Nenseth, V. (2015). Home, car use, and vacation: the structure of environmentally significant individual behavior. Environ. Behav. 47, 436-473. doi: 10.1177/0013916514525038

Brick, C., and Lai, C. K. (2018). Explicit (but not implicit) environmentalist identity predicts pro-evironmental behavior and policy preferences. J. Environ. Psychol. 58, 8-17. doi: 10.1016/j.jenvp.2018.07.003

Brick, C., and Lewis, G. J. (2016). Unearthing the "green" personality: core traits predict environmentally friendly behavior. Environ. Behav. 48, 635-658. doi: $10.1177 / 0013916514554695$

Brick, C., Sherman, D. K., and Kim, H. S. (2017). "Green to be seen" and "brown to keep down": visibility moderates the effect of identity on pro-environmental behavior. J. Environ. Psychol. 51, 226-238. doi: 10.1016/j.jenvp.2017.04.004

Brooks, J. S., and Wilson, C. (2015). The influence of contextual cues on the perceived status of consumption-reducing behavior. Ecol. Econ. 117, 108-117. doi: 10.1016/j.ecolecon.2015.06.015

Bruni, C. M., and Schultz, P. W. (2010). Implicit beliefs about self and nature: evidence from an IAT game. J. Environ. Psychol. 30, 95-102. doi: 10.1016/j.jenvp.2009.10.004

Camerer, C., and Hogarth, R. M. (1999). The effects of financial incentives in experiments: a review and capital-labor-production framework. J. Risk Uncertain. 19, 7-42. doi: 10.1023/A:1007850605129

Cerri, J., Thøgersen, J., and Testa, F. (2019). Social desirability and sustainable food research: a systematic literature review. Food Qual. Prefer. 71, 136-140. doi: 10.1016/j.foodqual.2018.06.013

*Chan, R. Y. K., Wong, Y. H., and Leung, T. K. P. (2008). Applying ethical concepts to the study of "green" consumer behavior: an analysis of Chinese consumers' intentions to bring their own shopping bags. J. Business Ethics 79, 469-481. doi: 10.1007/s10551-007-9410-8

*Chao, Y. L., and Lam, S. P. (2011). Measuring responsible environmental behavior: Self-reported and other-reported measures and their differences in testing a behavioral model. Environ. Behav. 43, 53-71. doi: $10.1177 / 0013916509350849$

Cohen, J. (1988). Statistical Power Analysis for the Behavioral Sciences, 2nd Edn, Hillsdale, NJ: Erlbaum.

*Cojuharenco, I., Cornelissen, G., and Karelaia, N. (2016). Yes, I can: Feeling connected to others increases perceived effectiveness and socially responsible behavior. J. Environ. Psychol. 48, 75-86. doi: 10.1016/j.jenvp.2016.09.002

Cooper, H. (1998). Synthesizing Research: A Guide for Literature Reviews, 3rd Edn, Thousand Oaks, CA: Sage.

Corral-Verdugo, V. (1997). Dual "realities" of conservation behaviour: self-reports vs. observations of re-use and recycling behaviour. J. Environ. Psychol. 17, 135-145. doi: 10.1006/jevp.1997.0048

Crowne, D. P., and Marlowe, D. (1960). A new scale of social desirability independent of psychopathology. J. Consult. Psychol. 24, 349-354. doi: $10.1037 /$ h0047358

Crowne, D. P., and Marlowe, D. (1964). The Approval Motive: Studies in Evaluative Dependence. New York, NY: Wiley.

Davis, C. G., Thake, J., and Vilhena, N. (2010). Social desirability biases in self-reported alcohol consumption and harms. Addict. Behav. 35, 302-311. doi: 10.1016/j.addbeh.2009.11.001

Davis, J. L., Green, J. D., and Reed, A. (2009). Interdependence with the environment: commitment, interconnectedness, and environmental behavior. J. Environ. Psychol. 29, 173-180. doi: 10.1016/j.jenvp.2008.11.001

DerSimonian, R., and Laird, N. (1986). Meta-analysis in clinical trials. Control. Clin. Trials 7, 177-188. doi: 10.1016/0197-2456(86)9 0046-2

Dodou, D., and de Winter, J. C. F. (2014). Social desirability is the same in offline, online, and paper surveys: a meta-analysis. Comput. Hum. Behav. 36, 487-495. doi: 10.1016/j.chb.2014.04.005

Dunlap, R. E., and Van Liere, K. D. (1978). The "New Environmental Paradigm": a proposed measuring instrument and preliminary results. J. Environ. Educ. 9, 10-19. doi: 10.1080/00958964.1978.10801875

Dunlap, R. E., van Liere, K. D., Mertig, A. G., and Jones, R. E. (2000). Measuring endorsement of the new ecological paradigm: a revised NEP scale. J. Soc. Iss. 56, 425-442. doi: 10.1111/0022-4537.00176

Ewert, A., and Galloway, G. (2009). Socially desirable responding in an environmental context: development of a domain specific scale. Environ. Educ. Res. 15, 55-70. doi: 10.1080/13504620802613504
Fox, S., and Schwartz, D. (2002). Social desirability and controllability in computerized and paper-and-pencil personality questionnaires. Comput. Hum. Behav. 18, 389-410. doi: 10.1016/S0747-5632(01)00057-7

Ganster, D. C., Hennessey, H. W., and Luthans, F. (1983). Social desirability response effects: three different models. Acad. Manage. J. 26, 955-966. doi: $10.2307 / 255979$

Gorissen, K., and Weijters, K. (2016). The negative footprint illusion: perceptual bias in sustainable food consumption. J. Environ. Psychol. 45, 50-65. doi: 10.1016/j.jenvp.2015.11.009

Griskevicius, V., Tybur, J. M., and van den Bergh, B. (2010). Going green to be seen: status, reputation, and conspicuous conservation. J. Pers. Soc. Psychol. 98, 392-404. doi: 10.1037/a0017346

Grønhøj, A., and Thøgersen, J. (2012). Action speaks louder than words: The effect of personal attitudes and family norms on adolescents' pro-environmental behaviour. J. Econ. Psychol. 33, 292-302. doi: 10.1016/j.joep.2011.10.001

Hahnel, U. J. J., and Brosch, T. (2018). Environmental trait affect. J. Environ. Psychol. 59, 94-106. doi: 10.1016/j.jenvp.2018.08.015

Haley, K. J., and Fessler, D. M. T. (2005). Nobody's watching? Subtle cues affect generosity in an anonymous economic game. Evol. Hum. Behav. 26, 245-256. doi: 10.1016/j.evolhumbehav.2005.01.002

Hartig, T., Kaiser, F. G., and Bowler, P. A. (2001). Psychological restoration in nature as a positive motivation for ecological behavior. Environ. Behav. 33, 590-607. doi: 10.1177/00139160121973142

*Hatfield, J., and Job, R. F. S. (2001). Optimism bias about environmental degradation: the role of the range of impact of precautions. J. Environ. Psychol. 21, 17-30. doi: 10.1006/jevp.2000.0190

*Haws, K. L., Winterich, K. P., and Naylor, R. W. (2014). Seeing the world through GREEN-tinted glasses: green consumption values and responses to environmentally friendly products. J. Consumer Psychol. 24, 336-354. doi: 10.1016/j.jcps.2013.11.002

Hedges, L. V., and Olkin, I. (1985). Statistical Methods for Meta-Analysis. Orlando, FL: Academic Press.

Hedges, L. V., and Vevea, J. L. (1998). Fixed- and random-effects models in meta-analysis. Psychol. Methods 3, 486-504. doi: 10.1037/1082-989X.3.4.486

Hoffman, E., McCabe, K., and Smith, V. L. (1996). Social distance and otherregarding behavior in dictator games. Am. Econ. Rev. 86, 653-660.

Hough, L. M., Eaton, N. K., Dunnette, M. D., Kamp, J. D., and McCloy, R. A. (1990). Criterion-related validities of personality constructs and the effect of response distortion on those validities. J. Appl. Psychol. 75, 581-595. doi: 10.1037/0021-9010.75.5.581

*Howell, A. J., Dopko, R. L., Passmore, H.-A., and Buro, K. (2011). Nature connectedness: associations with well-being and mindfulness. Pers. Individ. Dif. 51, 166-171. doi: 10.1016/j.paid.2011.03.037

Hunter, J. E., and Schmidt, E. L. (1990). Methods of Meta-Analysis: Correcting Error and Bias in Research Findings. Newbury Park, CA: Sage.

Joinson, A. (1999). Social desirability, anonymity, and Internet-based questionnaires. Behav. Res. Methods Instrum. Comput. 31, 433-438. doi: $10.3758 /$ BF03200723

Juhl, H. J., Fenger, M. H. J., and Thøgersen, J. (2017). Will the consistent organic food consumer step forward? An empirical analysis. J. Consumer Res. 4, 519-535. doi: 10.1093/jcr/ucx052

Kaiser, F. G., Hartig, T., Brügger, A., and Duvier, C. (2013). Environmental protection and nature as distinct attitudinal objects: an application of the Campbell paradigm. Environ. Behav. 45, 369-398. doi: 10.1177/0013916511422444

*Kaiser, F. G., Ranney, M., Hartig, T., and Bowler, P. A. (1999). Ecological behavior, environmental attitude, and feelings of responsibility for the environment. Eur. Psychol. 4, 59-74. doi: 10.1027//1016-9040.4.2.59

Kaiser, F. G., Schultz, P. W., Berenguer, J., Corral-Verdugo, V., and Tankha, G. (2008). Extending planned environmentalism: anticipated guilt and embarrassment across cultures. Eur. Psychol. 13, 288-297. doi: 10.1027/1016-9040.13.4.288

Klaiman, K., Ortega, D. L., and Garnache, C. (2016). Consumer preferences and demand for packaging material and recyclability. Resour. Conserv. Recycling 115, 1-8. doi: 10.1016/j.resconrec.2016.08.021

Kormos, C., and Gifford, R. (2014). The validity of self-report measures of proenvironmental behavior: a meta-analytic review. J. Environ. Psychol. 40, 359-371. doi: 10.1016/j.jenvp.2014.09.003 
Korndörfer, M., Krumpal, I., and Schmukle, S. C. (2014). Measuring and explaining tax evasion: improving self-reports using the crosswise model. J. Econ. Psychol. 45, 18-32. doi: 10.1016/j.joep.2014.08.001

Krumpal, I. (2013). Determinants of social desirability bias in sensitive surveys: a literature review. Qual. Quant. 47, 2025-2047. doi: 10.1007/s11135-011-9640-9

Lacasse, K. (2019). Can't hurt, might help: Examining the spillover effects from purposefully adopting a new pro-environmental behavior. Environ. Behav. 51, 259-287. doi: 10.1177/0013916517748164

Lange, F., and Dewitte, S. (2019). Measuring pro-environmental behavior: review and recommendations. J. Environ. Psychol. 63, 92-100. doi: 10.1016/j.jenvp.2019.04.009

*Lapinski, M. K., Zhuang, J., Koh, H., and Shi, J. (2017). Descriptive norms and involvement in health and environmental behaviors. Commun. Res. 44, 367-387. doi: 10.1177/0093650215605153

Lautenschlager, G. J., and Flaherty, V. L. (1990). Computer administration of questions: more desirable or more social desirability? J. Appl. Psychol. 75, 310-314. doi: 10.1037/0021-9010.75.3.310

*Lavergne, K. J., and Pelletier, L. G. (2015). Predicting individual differences in the choice of strategy to compensate for attitude-behaviour inconsistencies in the environmental domain. J. Environ. Psychol. 44, 135-148. doi: $10.1016 /$ j.jenvp.2015.10.001

Li, A., and Bagger, J. (2006). Using the BIDR to distinguish the effects of impression management and self-deception on the criterion validity of personality measures: a meta-analysis. Int. J. Select. Assess. 14, 131-141. doi: $10.1111 / j .1468-2389.2006 .00339 . x$

Lusk, J. L., and Norwood, F. B. (2010). Direct versus indirect questioning: an application to the well-being of farm animals. Soc. Indic. Res. 96, 551-565. doi: 10.1007/s11205-009-9492-z

Manning, M. (2009). The effects of subjective norms on behaviour in the theory of planned behaviour: a meta-analysis. Br. J. Soc. Psychol. 48, 649-705. doi: 10.1348/014466608X393136

Martin, C., and Czellar, S. (2017). Where do biospheric values come from? A connectedness to nature perspective. J. Environ. Psychol., 52, 56-68. doi: 10.1016/j.jenvp.2017.04.009

Matthies, E., Selge, S., and Klöckner, C. A. (2012). The role of parental behaviour for the development of behaviour specific environmental norms: the example of recycling and re-use behaviour. J. Environ. Psychol. 32, 277-284. doi: 10.1016/j.jenvp.2012.04.003

*Mayer, F. S., and Frantz, C. M. (2004). The connectedness to nature scale: a measure of individuals' feeling in community with nature. J. Environ. Psychol. 24, 503-515. doi: 10.1016/j.jenvp.2004.10.001

McGrath, R. E., Mitchell, M., Kim, B. H., and Hough, L. (2010). Evidence for response bias as a source of error variance in applied assessment. Psychol. Bull. 136, 450-470. doi: 10.1037/a0019216

Meade, A. W., and Craig, S. B. (2012). Identifying careless responses in survey data. Psychol. Methods 17, 437-455. doi: 10.1037/a0028085

*Milfont, T. L. (2009). The effects of social desirability on self-reported environmental attitudes and ecological behaviour. Environmentalist 29, 263-269. doi: 10.1007/s10669-008-9192-2

Milfont, T. L., and Duckitt, J. (2010). The Environmental Attitudes Inventory: a valid and reliable measure to assess the structure of environmental attitudes. J. Environ. Psychol. 30, 80-94. doi: 10.1016/j.jenvp.2009.09.001

*Moon, S., Bergey, P. K., Bove, L. L., and Robinson, S. (2016). Message framing and individual traits in adopting innovative, sustainable products (ISPs): evidence from biofuel adoption. J. Bus. Res. 69, 3553-3560. doi: 10.1016/j.jbusres.2016.01.029

*Mydock, S., Pervan, S. J., Almubarak, A. F., Johnson, L., and Kortt, M. (2018). Influence of made with renewable energy appeal on consumer behaviour. Market. Intell. Plann. 36, 32-48. doi: 10.1108/MIP-06-2017-0116

Nederhof, A. J. (1985). Methods of coping with social desirability bias: a review. Eur. J. Soc. Psychol. 15, 263-280. doi: 10.1002/ejsp.2420150303

*O'Brien, L. V., Meis, J., Anderson, R. C., Rizio, S. M., Ambrose, M., Bruce, G., et al. (2018). Low carbon readiness index: a short measure to predict private low carbon behaviour. J. Environ. Psychol. 57, 34-44. doi: 10.1016/j.jenvp.2018.06.005

*Oerke, B., and Bogner, F. X. (2013). Social desirability, environmental attitudes, and general ecological behaviour in children. Int. J. Sci. Educ. 35, 713-730. doi: 10.1080/09500693.2011.566897
Ones, D. S., Viswesvaran, C., and Reiss, A. D. (1996). Role of social desirability in personality testing in personnel selection: the red herring. J. Appl. Psychol. 81, 660-679. doi: 10.1037/0021-9010.81.6.660

Oppenheimer, D. M., Meyvis, T., and Davidenko, N. (2009). Instructional manipulation checks: detecting satisficing to increase statistical power. J. Exp. Soc. Psychol. 45, 867-872. doi: 10.1016/j.jesp.2009.03.009

*Panno, A., Carrus, G., Maricchiolo, F., and Mannetti, L. (2015). Cognitive reappraisal and pro-environmental behavior: the role of global climate change perception. Eur. J. Soc. Psychol. 45, 858-867. doi: 10.1002/ejsp.2162

Paulhus, D. L. (1981). Control of social desirability in personality inventories: principal-factor deletion. J. Res. Pers.15, 383-388. doi: 10.1016/0092-6566(81)90035-0

Paulhus, D. L. (1984). Two-component models of socially desirable responding. $J$. Pers. Soc. Psychol. 46, 598-609. doi: 10.1037/0022-3514.46.3.598

Paulhus, D. L. (1991). "Measurement and control of response bias," in Measures of Personality and Social Psychological Attitudes, eds J. P. Robinson, P. R. Shaver, and L. S. Wrightsman (San Diego, CA: Academic Press), 17-59. doi: 10.1016/B978-0-12-590241-0.50006-X

Paunonen, S. V., and LeBel, E. P. (2012). Socially desirable responding and its elusive effects on the validity of personality assessments. J. Personal. Soc. Psychol. 103, 158-175. doi: 10.1037/a0028165

*Pepper, M., Jackson, T., and Uzzell, D. (2011). An examination of christianity and socially conscious and frugal consumer behaviors. Environ. Behav. 43, 274-290. doi: $10.1177 / 0013916510361573$

*Pfattheicher, S., Sassenrath, C., and Schindler, S. (2016). Feelings for the suffering of others and the environment: compassion fosters proenvironmental tendencies. Environ. Behav. 48, 929-945. doi: 10.1177/0013916515574549

*Raineri, N., and Paille, P. (2016). Linking corporate policy and supervisory support with environmental citizenship behaviors: the role of employee environmental beliefs and commitment. J. Bus. Ethics 137, 129-148. doi: 10.1007/s10551-015-2548-x

Rasinski, K. A., Willis, G. B., Baldwin, A. K., Yeh, W. C., and Lee, L. (1999). Methods of data collection, perceptions of risks and losses, and motivation to give truthful answers to sensitive survey questions. Appl. Cogn. Psychol. $13,465-484$.

Richard, F. D., Bond, C. F. Jr., and Stokes-Zoota, J. J. (2003). One hundred years of social psychology quantitatively described. Rev. Gen. Psychol. 7, 331-363. doi: 10.1037/1089-2680.7.4.331

Schultz, P. W., Nolan, J. M., Cialdini, R. B., Goldstein, N. J., and Griskevicius, V. (2007). The constructive, destructive, and reconstructive power of social norms. Psychol. Sci. 18, 429-434. doi: 10.1111/j.1467-9280.2007. 01917.x

Seebauer, S., Fleiss, J., and Schweighart, M. (2017). A household is not a person: consistency of pro-environmental behavior in adult couples and the accuracy of proxy-reports. Environ. Behav. 49, 603-637. doi: 10.1177/0013916516663796

Singer, E., Hippler, H. J., and Schwarz, N. (1992). Confidentiality assurances in surveys: reassurance or threat? Int. J. Public Opin. Res. 4, 256-268. doi: 10.1093/ijpor/4.3.256

*Sörqvist, P., Haga, A., Holmgren, M., and Hansla, A. (2015a). An eco-label effect in the built environment: performance and comfort effects of labeling a light source environmentally friendly. J. Environ. Psychol. 42, 123-127. doi: 10.1016/j.jenvp.2015.03.004

*Sörqvist, P., Haga, A., Langeborg, L., Holmgren, M., Wallinder, M., Nöstl, A., et al. (2015b). The green halo: mechanisms and limits of the eco-label effect. Food Qual. Prefer. 43, 1-9. doi: 10.1016/j.foodqual.2015.02.001

Spearman, C. (1904). The proof and measurement of association between two things. Am. J. Psychol.15, 72-101. doi: 10.2307/1412159

Tam, K.-P. (2013a). Concepts and measures related to connection to nature: similarities and differences. J. Environ. Psychol. 34, 64-78. doi: 10.1016/j.jenvp.2013.01.004

*Tam, K.-P. (2013b). Dispositional empathy with nature. J. Environ. Psychol. 35, 92-104. doi: 10.1016/j.jenvp.2013.05.004

Thøgersen, J. (2006). Norms for environmentally responsible behaviour: an extended taxonomy. J. Environ. Psychol. 26, 247-261. doi: 10.1016/j.jenvp.2006.09.004

Thomas, G. O., and Walker, I. (2016). The development and validation of an implicit measure based on biospheric values. Environ. Behav. 48, 659-685. doi: $10.1177 / 0013916514553836$ 
*Ture, R. S., and Ganesh, M. P. (2018). Pro-environmental behaviours at workplace: an empirical study in Indian manufacturing organizations. Benchmark. Int. J. 25, 3743-3766. doi: 10.1108/BIJ-07-2017-0193

van de Mortel, T. F. (2008). Faking it: social desirability response bias in self-report research. Aust. J. Adv. Nursing 25, 40-48. Available online at: https://www.ajan. com.au/archive/ajan_25.4.html and s https://www.ajan.com.au/archive/Vol25/ Vol_25-4_vandeMortel.pdf.

Vesely, S., and Klöckner, C. A. (2018). Global social norms and environmental behavior. Environ. Behav. 50, 247-272. doi: 10.1177/00139165177 02190

Warner, S. L. (1965). Randomized response: a survey technique for eliminating evasive answer bias. J. Am. Stat. Assoc. 60, 63-69. doi: 10.1080/01621459.1965.10480775

Whitmarsh, L., and O'Neill, S. (2010). Green identity, green living? The role of pro-environmental self-identity in determining consistency across diverse pro-environmental behaviours. J. Environ. Psychol. 30, 305-314. doi: 10.1016/j.jenvp.2010.01.003

*Wiseman, M., and Bogner, F. X. (2003). A higher-order model of ecological values and its relationship to personality. Pers. Individ. Dif. 34, 783-794. doi: 10.1016/S0191-8869(02)00071-5

*Wu, B., and Yang, Z. (2018). The impact of moral identity on consumers' green consumption tendency: the role of perceived responsibility for environmental damage. J. Environ. Psychol. 59, 74-84. doi: 10.1016/j.jenvp.2018.08.011

* References marked with an asterisk were included in the meta-analyses.
Zemore, S. E. (2012). The effect of social desirability on reported motivation, substance use severity, and treatment attendance. J. Subst. Abuse Treat. 42, 400-412. doi: 10.1016/j.jsat.2011.09.013

*Zhang, J. W., Howell, R. T., and Iyer, R. (2014). Engagement with natural beauty moderates the positive relation between connectedness with nature and psychological well-being. J. Environ. Psychol. 38, 55-63. doi: 10.1016/j.jenvp.2013.12.013

Zhang, W. Z., Goodale, E., and Chen, J. (2014). How contact with nature affects children's biophilia, biophobia and conservation attitude in China. Biol. Conserv. 177, 109-116. doi: 10.1016/j.biocon.2014 06.011

*Zhao, H., Zhang, H., Xu, Y., Lu, J., and He, W. (2018). Relation between awe and environmentalism: the role of social dominance orientation. Front. Psychol. 9:2367. doi: 10.3389/fpsyg.2018.02367

Conflict of Interest: The authors declare that the research was conducted in the absence of any commercial or financial relationships that could be construed as a potential conflict of interest.

Copyright (C) 2020 Vesely and Klöckner. This is an open-access article distributed under the terms of the Creative Commons Attribution License (CC BY). The use, distribution or reproduction in other forums is permitted, provided the original author(s) and the copyright owner(s) are credited and that the original publication in this journal is cited, in accordance with accepted academic practice. No use, distribution or reproduction is permitted which does not comply with these terms. 


\section{APPENDIX}

\section{Search String Used to Search the Web of Science Database}

TS $=($ ("social* desirab*” OR desirab* OR deception OR deceive OR misreport* OR overreport* OR misrepresent* OR distort* OR denial OR acquiesc* OR "impression management" OR self-disclosure OR disclos* OR selfenhancement OR Edwards OR Marlowe-Crowne OR CrowneMarlowe OR Paulhus OR Wiggins OR MCSD OR MCSD OR MCSDS OR MC-SDS OR BIDR OR RD-16) AND (saving OR save OR conserv* OR preserv* OR consum* OR proenvironmental OR environment* friendly OR "environmentally conscious" OR "environmentally responsible” OR ecological OR sustain* OR reuse OR green OR renewable OR PEB OR GEB OR recycl* OR waste OR energy OR electricity OR water OR purchas* OR travel OR transport* OR "organic food" OR "local food" OR meat
OR mobility OR "car use" OR activis* OR "climate change" OR "global warming" OR mitigat* OR value-belief-norm OR "value belief norm" OR VBN OR "comprehensive action determination model" OR CADM)) Refined by: WEB OF SCIENCE CATEGORIES: (MANAGEMENT OR ECOLOGY OR ENVIRONMENTAL SCIENCES OR GREEN SUSTAINABLE SCIENCE TECHNOLOGY OR ECONOMICS OR MULTIDISCIPLINARY SCIENCES OR PSYCHOLOGY MULTIDISCIPLINARY OR BUSINESS OR SOCIAL SCIENCES INTERDISCIPLINARY OR ENVIRONMENTAL STUDIES OR NUTRITION DIETETICS) Timespan: All years. Indexes: SCI-EXPANDED, SSCI, A\&HCI, CPCI-S, CPCI-SSH, ESCI. 